BMJ Open

Diabetes

Research

\& Care

\title{
Variability in preventive care practices among US adults with diabetes mellitus
}

\author{
Lorena Baccaglini, ${ }^{1}$ Adams Kusi Appiah, ${ }^{2}$ Mahua Ray, ${ }^{2}$ Fang Yu (1) ${ }^{2}$
}

To cite: Baccaglini L, Kusi Appiah A, Ray M, et al. Variability in preventive care practices among US adults with diabetes mellitus. BMJ Open Diab Res Care 2021;9:e001861. doi:10.1136/ bmjdrc-2020-001861

Received 25 August 2020 Revised 30 November 2020 Accepted 20 December 2020
Check for updates

(C) Author(s) (or their employer(s)) 2021. Re-use permitted under CC BY-NC. No commercial re-use. See rights and permissions. Published by BMJ.

${ }^{1}$ Epidemiology, University of Nebraska Medical Center, Omaha, Nebraska, USA ${ }^{2}$ Biostatistics, University of Nebraska Medical Center, Omaha, Nebraska, USA

Correspondence to Dr Fang Yu; Fangyu@unmc.edu

\section{ABSTRACT}

Introduction Patients with diabetes are advised to follow standard medical care including daily blood glucose and foot checks, eye examinations with pupil dilation, and cholesterol checks to prevent diabetes-related complications. It is unclear how these practices currently vary across different US population subgroups. The objective of this study was to assess variation in overall and individual diabetes care practices and identify specific factors associated with differences in these practices in a representative sample of US diabetic adults.

Research design and methods Cross-sectional data were from the 2017 Behavioral Risk Factor Surveillance System. Survey logistic regression was used to account for the complex sampling design.

Results Among 30780 eligible participants, 8957 (equivalent to $28 \%$ of the target population) followed all four diabetes care practices. Insulin-dependent participants had higher adjusted odds (adjusted $\mathrm{OR}=2.95$; $95 \% \mathrm{Cl} 2.62$ to 3.31 ) of following all four diabetic care practices compared with those who did not. Cost-related variables (having healthcare coverage and/or a personal doctor) were positively associated with diabetes care practices, with the strongest association observed for adherence to more costly practices (annual eye examination and cholesterol check) versus less costly ones (daily blood glucose check, daily foot check).

Conclusions Our findings suggest the need for diabetes care practice-specific and population subgroup-specific public health interventions to encourage early adherence to diabetic care practices and reduce complications.

\section{INTRODUCTION}

The number of adults with diabetes worldwide has quadrupled since 1980, reaching 422 million in $2014 .{ }^{1}$ In 2016, an estimated 1.6 million deaths were directly caused by diabetes, and another 2.2 million deaths were attributable to hyperglycemia in $2012 .{ }^{1}$ According to the Centers for Disease Control and Prevention $(\mathrm{CDC})^{2}$ and the American Diabetes Association (ADA) Standards of Medical Care in Diabetes, ${ }^{3}$ patients with diabetes should perform daily blood glucose self-tests, daily foot self-checks, dilated retinal examinations and cholesterol checks at least annually. In 2010, $63 \%$ of US diabetic adults reported daily glucose monitoring, $71 \%$ performed daily foot checks and $62 \%$ had annual eye examinations. ${ }^{4}$ Carroll et al

\section{Significance of this study}

What is already known about this subject?

- During 2001-2010, patients with diabetes showed a steady increase in self-monitoring of blood glucose, although they had declines in annual eye examinations and self-foot checks.

- In $2010,63 \%$ of US diabetic adults reported daily glucose monitoring, $71 \%$ performed daily foot checks and $62 \%$ had annual eye examinations.

- In 2009-2010, approximately $68 \%$ of adults reported having their cholesterol checked in the preceding 5 years.

What are the new findings?

- Concurrent utilization of all four diabetic care practices was low (less than one-third), although a higher percentage of participants followed individual practices, suggesting that different patients with diabetes may follow different practices.

- In 2017, daily foot checks were less common (60\%) and annual eye examinations more common (69\%) compared with 2010 data.

- Overall, diabetic care practices were more common among non-Hispanic Blacks, insulin users and individuals with obesity or retinopathy, which might have been related to greater disease severity in these subgroups.

- Risk factors for low utilization were specific to the type of diabetes care practice. Diabetes care practices more strongly linked to cost and access to care (eg, eye examinations) showed lower utilization compared with less expensive home-based practices (eg, foot check).

How might these results change the focus of research or clinical practice?

- Public health interventions should focus on early adherence to diabetic care practices among high-risk population subgroups to reduce complications.

- Improved adherence may require diabetes care practice-specific strategies, such as improved access to care for costly clinic-based practices and improved education for home-based practices.

reported that during the 2009-2010 National Health and Nutrition Examination Survey (NHANES), approximately $68 \%$ of adults had their cholesterol checked in the preceding 5 years. $^{5}$ 
Glycemic control is directly associated with the onset and progression of retinopathy, nephropathy and neuropathy. ${ }^{6}$ Self-monitoring of blood glucose levels is a useful strategy to maintain appropriate glycemic control, and adjust dietary intake, physical activity and medication dosage accordingly. ${ }^{7}$

Around $15 \%-25 \%$ of patients with diabetes are expected to develop foot ulcers during their lifetime. ${ }^{8}$ Foot ulceration and infection is a preventable condition among people with diabetes. A prospective study with 11-year follow-up in a European general hospital reported a $70 \%$ reduction in total diabetic amputations after the introduction of a multidisciplinary foot team and continuous prospective audits. ${ }^{9}$ Effective early management of diabetic foot ulceration can reduce the severity of complications and improve overall quality of life. ${ }^{10}$

Routine eye examinations are essential for patients with diabetes, as they are at higher risk for ocular complications, including glaucoma, ${ }^{11}$ cataract, ${ }^{12}$ and diabetic retinopathy (DR). DR is a common microvascular complication of diabetes and the leading cause of preventable blindness among US adults. ${ }^{13}$ According to the 2005-2008 NHANES, $62.5 \%$ of US adults with self-reported diabetes had an annual pupil dilation, though the examination was more common among those with more severe eye disease. ${ }^{14}$ Older age, residing in the US for 5 or more years, and having insurance have been positively associated with having a dilated eye examination among Hispanics. ${ }^{15}$ In the general US adult population, annual eye examinations are also more frequent among those with more education and higher income. ${ }^{16}$

Diabetic individuals are at higher risk for hypercholesterolemia, which can lead to cardiovascular disease and premature death. Routine cholesterol checks are essential for monitoring and timely treatment of cholesterol abnormalities among diabetic individuals.

A previous study of US trends in receiving diabetic clinical and self-care from 2001 to 2010 indicated that, although patients with diabetes showed a steady increase in selfmonitoring of blood glucose, they had declines in annual eye examinations and self-foot checks. ${ }^{4}$ It is important to re-evaluate compliance with diabetic care practices after 7 years to determine whether these trends continue. Additionally, patients with diabetes may have individual preferences for certain diabetic care practices; therefore, it is worth assessing both individual and overall patterns of these practices. The goal of this paper was to identify and quantify the factors associated with preventive care practices among patients with diabetes using 2017 Behavioral Risk Factor Surveillance System (BRFSS) survey data.

\section{RESEARCH DESIGN AND METHODS}

Data source and sample

Data were from the 2017 BRFSS, a phone-based national survey conducted by the CDC using a complex multistage probability sample representative of the civilian non-institutionalized US population. ${ }^{17}$ The analyses included adults 18 years or older with diabetes mellitus and complete data on the variables of interest. Pregnant women were excluded because they had missing body mass index (BMI) data. Participants with gestational diabetes, pre-diabetes, or borderline diabetes were excluded.

\section{Outcome measure}

Routine assessment of glycemia, foot checks, eye examinations, and cholesterolemia monitoring are among the ADA and CDC's recommended preventive care practices for patients with diabetes. The primary outcomes were whether BRFSS participants checked their blood glucose and feet on average at least once a day and had an ophthalmic examination with dilation and cholesterolemia measured by a health professional at least once in the last 12 months. Participants who followed all four diabetes care practices were classified as adherent, or non-adherent otherwise, to this set of preventive care practices.

\section{Independent variables}

Independent variables included self-reported information on demographic, socioeconomic, health and access-to-care factors. ${ }^{18} 19$ Demographic factors included age, sex, race/ ethnicity, and marital status. Socioeconomic factors included education, employment status, smoking, exercise in the past 30 days, and alcohol intake (at least one drink of any alcoholic beverage such as beer, wine, a malt beverage or liquor in the past 30 days). Health factors included BMI, current insulin use, and history of retinopathy. Access-to-care factors included healthcare coverage (including health insurance, prepaid plans such as health maintenance organizations, or government plans such as Medicare, or Indian Health Service), having a personal doctor, and perceiving cost as a barrier to medical care.

\section{Analytical methods}

We performed a complete case analysis. Counts and percentages were used to describe categorical data overall and by disease severity (defined based on current insulin use and history of retinopathy). Univariate and multivariate logistics regression models were used to calculate crude (OR) or adjusted ORs (AOR) with 95\% CI for the association between the independent variables and performance of all four selected diabetes care practices. The final model was identified via backward variable selection using $p$ values $>0.1$ for removal. Separate subanalyses included individual diabetes care practices using predictors identified in the overall final model. All analyses were conducted using the SAS (V.9.4, SAS Institute) procedures SURVEYFREQ and SURVEYLOGISTIC to account for the complex, multistage survey sampling design.

The analyses used BRFSS, a publicly available data set containing anonymized data collected with informed consent. 


\section{RESULTS}

The final number of eligible participants was 30780 (figure 1). Approximately $30 \%$ of participants (corresponding to 3720346 or $28 \%$ of the US diabetic population) had followed all four diabetic care practices (ie, at least daily blood glucose and foot checks, an annual eye examination, and an annual cholesterol check) in the prior 12 months.

Non-Hispanic Black participants, current insulin users, or individuals with retinopathy were the subgroups with the highest percentage (ie, over 35\%) of individuals performing all four diabetic care practices. A lower percentage of participants who were younger, employed, current smokers, had consumed alcohol during the prior 30 days, had a lower BMI, had less than a high school education, or had no personal doctor performed diabetic care practices. The lowest percentage (16\%) of participants performing diabetic care practices was individuals without healthcare coverage (table 1 ).

After adjusting for other variables, participants who used insulin had three times the odds (AOR=2.95; $95 \%$ CI 2.62 to 3.31) of performing all four diabetic care practices compared with those who did not use insulin. Participants with retinopathy also had higher adjusted odds of adherence to all four diabetic care practices $(\mathrm{AOR}=1.17$; 95\% CI 1.01 to 1.34 ). The adjusted odds of practicing diabetes care were also substantially higher among those with versus without healthcare coverage ( $\mathrm{AOR}=1.85$; $95 \%$ CI 1.33 to 2.56) and among non-Hispanic Blacks compared with non-Hispanic Whites (AOR=1.77; 95\% CI 1.48 to 2.10). Lower AORs of performing diabetic care practices were observed for participants with no personal doctor, less than high school education, alcohol consumption or lack of exercise in the past 30 days, or who were employed, or not in a relationship (table 2). The percentage of individuals performing daily blood glucose checks was $61 \%$, daily foot checks $60 \%$, annual eye examination $69 \%$ and annual cholesterol check $93 \%$ (figure 2). However, adherence varied by current insulin use and retinopathy. Specifically, individuals treated with insulin and with a history of retinopathy were more likely to perform daily blood glucose and foot checks as well as annual eye examinations and cholesterol checks compared with those not treated with insulin or without retinopathy.

Subanalyses identified predictors of individual diabetes care practices. Current insulin use was strongly associated with performance of daily blood glucose checks $(\mathrm{AOR}=8.57 ; 95 \%$ CI 7.35 to 9.98$)$. Negative associations were observed between cost-related variables (no healthcare coverage and/or no personal doctor) and performance of all four of these diabetes care practices, with the strongest association observed for adherence to more costly practices (annual eye examination and cholesterol check) versus less costly practices (daily blood glucose and foot check). Obese participants were more adherent to practices primarily related to daily foot check and annual cholesterol checks compared with those with lower BMI. Participants with lower education had higher odds of performing daily glucose checks, and lower odds of having an annual eye examination compared with those with higher education (table 3 ).

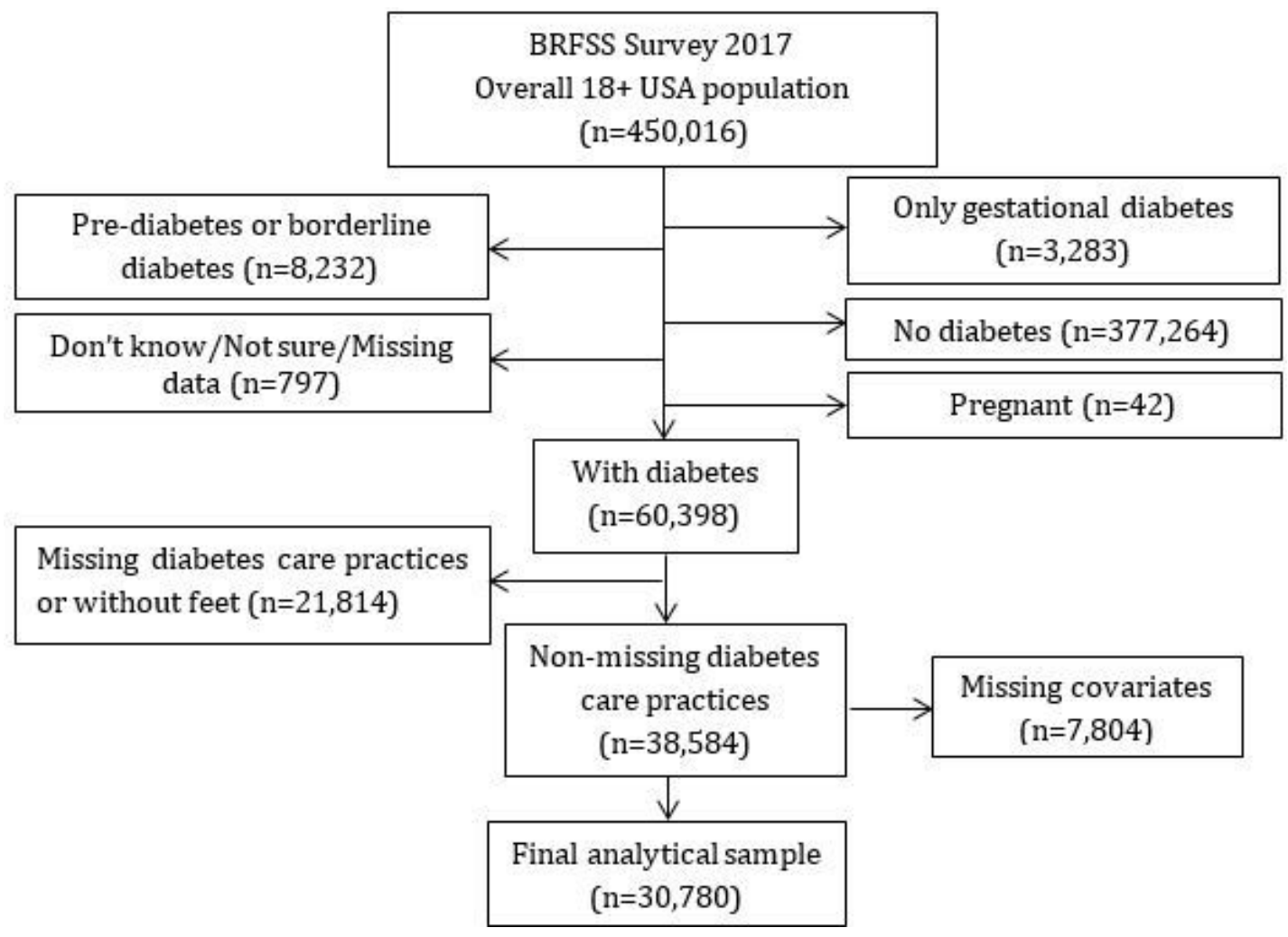

Figure 1 Flow chart. BRFSS, Behavioral Risk Factor Surveillance System. 
Table 1 Demographic and socioeconomic characteristics by diabetes care practice

\begin{tabular}{|c|c|c|c|c|}
\hline \multirow[b]{4}{*}{ Characteristics } & \multicolumn{4}{|c|}{ Diabetes care practice $(n=30780 ; N=13113662)$} \\
\hline & \multicolumn{2}{|c|}{ Yes ( $n=8957 ; N=3720$ 346) } & \multicolumn{2}{|c|}{ No $(n=21823 ; N=9393316)$} \\
\hline & Sample frequency & Population estimate & Sample frequency & Population estimate \\
\hline & $\mathbf{n}$ & N (thousand; \%) & $\mathbf{n}$ & N (thousand; \%) \\
\hline \multicolumn{5}{|l|}{ Sex } \\
\hline Male & 3903 & $1843.6(27.3)$ & 10440 & $4915.7(72.7)$ \\
\hline Female & 5054 & $1876.8(29.5)$ & 11383 & $4477.6(70.5)$ \\
\hline \multicolumn{5}{|l|}{ Age } \\
\hline $18-44$ & 394 & $336.8(22.8)$ & 1392 & $1142.0(77.2)$ \\
\hline $45-64$ & 3335 & $1677.1(28.4)$ & 8601 & $4230.1(71.6)$ \\
\hline $65+$ & 5228 & $1706.5(29.8)$ & 11830 & $4021.2(70.2)$ \\
\hline \multicolumn{5}{|l|}{ Body mass index $(\mathrm{BMI})^{\star}$} \\
\hline Underweight/normal weight & 1199 & $440.9(25.2)$ & 3132 & $1311.8(74.8)$ \\
\hline Overweight & 2716 & $1098.7(27.6)$ & 6899 & $2885.0(72.4)$ \\
\hline Obese & 5042 & $2180.8(29.6)$ & 11792 & $5196.5(70.4)$ \\
\hline \multicolumn{5}{|l|}{ Race/ethnicity } \\
\hline Non-Hispanic White & 6190 & $2305.4(27.1)$ & 16147 & $6208.0(72.9)$ \\
\hline Non-Hispanic Black & 1626 & $865.5(38.2)$ & 2727 & $1401.6(61.8)$ \\
\hline Non-Hispanic other & 560 & $163.9(22.9)$ & 1442 & $551.4(77.1)$ \\
\hline Hispanic & 581 & $385.5(23.8)$ & 1507 & $1232.3(76.2)$ \\
\hline \multicolumn{5}{|l|}{ Marital status } \\
\hline Couple† & 4399 & $2107.5(28.7)$ & 10909 & $5244.8(71.3)$ \\
\hline Widowed & 1914 & $575.1(30.2)$ & 4176 & $1330.9(69.8)$ \\
\hline Divorced/separated/never married & 2644 & $1037.8(26.9)$ & 6738 & $2817.6(73.1)$ \\
\hline \multicolumn{5}{|l|}{ Education } \\
\hline$<$ High school & 933 & $571.5(24.2)$ & 2315 & $1788.6(75.8)$ \\
\hline High school & 2930 & $1273.0(30.4)$ & 7026 & $2909.2(69.6)$ \\
\hline Some college/technical & 2659 & $1232.5(29.7)$ & 6345 & $2915.8(70.3)$ \\
\hline College or above & 2435 & $643.3(26.5)$ & 6137 & $1779.7(73.5)$ \\
\hline \multicolumn{5}{|l|}{ Employment } \\
\hline Employed & 2110 & $992.2(23.0)$ & 6534 & $3329.5(77.0)$ \\
\hline Home maker/student/retired & 4849 & $1725.2(30.4)$ & 11026 & $3958.1(69.6)$ \\
\hline Not employed/unable to work & 1998 & $1003.0(32.3)$ & 4263 & $2105.7(67.7)$ \\
\hline \multicolumn{5}{|l|}{ Smoking status } \\
\hline Current & 1065 & $498.5(24.5)$ & 3198 & $1536.3(75.5)$ \\
\hline Former & 3284 & $1343.0(28.9)$ & 8075 & $3307.9(71.1)$ \\
\hline Never & 4608 & $1878.9(29.2)$ & 10550 & $4549.1(70.8)$ \\
\hline \multicolumn{5}{|l|}{ Alcohol intake in the past 30 days } \\
\hline Yes & 2593 & $1080.2(23.6)$ & 8104 & $3492.3(76.4)$ \\
\hline No & 6364 & 2640.1 (30.9) & 13719 & $5901.0(69.1)$ \\
\hline \multicolumn{5}{|l|}{ Self-reported general health } \\
\hline Good/better & 4887 & $1986.2(27.7)$ & 12811 & 5185.7 (72.3) \\
\hline Fair/poor & 4070 & $1734.2(29.2)$ & 9012 & $4207.6(70.8)$ \\
\hline \multicolumn{5}{|l|}{ Healthcare coverage $\neq$} \\
\hline Yes & 8707 & $3577.1(29.2)$ & 20721 & $8665.6(70.8)$ \\
\hline No & 250 & $143.3(16.4)$ & 1102 & $727.7(83.6)$ \\
\hline
\end{tabular}




\begin{tabular}{|c|c|c|c|c|}
\hline \multirow[b]{4}{*}{ Characteristics } & \multicolumn{4}{|c|}{ Diabetes care practice $(n=30780 ; N=13113662)$} \\
\hline & \multicolumn{2}{|c|}{ Yes (n=8957; N=3 720346$)$} & \multicolumn{2}{|c|}{ No (n=21823; N=9 393 316) } \\
\hline & Sample frequency & Population estimate & Sample frequency & Population estimate \\
\hline & $\mathbf{n}$ & N (thousand; \%) & $\mathbf{n}$ & $\mathbf{N}$ (thousand; \%) \\
\hline \multicolumn{5}{|c|}{ Exercise in the past 30 days } \\
\hline Yes & 5465 & $2288.2(29.4)$ & 12872 & $5496.5(70.6)$ \\
\hline No & 3492 & $1432.2(26.9)$ & 8951 & $3896.8(73.1)$ \\
\hline \multicolumn{5}{|c|}{ Current insulin user§ } \\
\hline Yes & 4537 & $1893.1(44.0)$ & 5439 & $2408.9(56.0)$ \\
\hline No & 4420 & $1827.3(20.7)$ & 16384 & $6984.4(79.3)$ \\
\hline \multicolumn{5}{|c|}{ Personal doctor/healthcare provider } \\
\hline Yes & 8683 & $3568.8(29.1)$ & 20517 & $8699.4(70.9)$ \\
\hline No & 274 & $151.5(17.9)$ & 1306 & $693.9(82.1)$ \\
\hline \multicolumn{5}{|c|}{ Could not see a doctor due to cost } \\
\hline Yes & 873 & $470.0(25.0)$ & 2617 & $1406.9(75.0)$ \\
\hline No & 8084 & $3250.3(28.9)$ & 19206 & $7986.4(71.1)$ \\
\hline \multicolumn{5}{|c|}{ History of retinopathy } \\
\hline Yes & 2130 & $914.4(35.6)$ & 3567 & $1653.1(64.4)$ \\
\hline No & 6827 & $2806.0(26.6)$ & 18256 & $7740.2(73.4)$ \\
\hline
\end{tabular}

Diabetes care practice was defined as adherence to all four practices (daily blood glucose checks, daily foot checks, annual eye examinations, and annual cholesterol checks). Population estimates ( $\mathrm{N}$ and \%) were calculated accounting for the complex study design.

${ }^{\star} \mathrm{BMI}$ : underweight/normal weight: $\mathrm{BMl}<25$, overweight: $25 \leq \mathrm{BMl}<30$, obese: $\mathrm{BMI} \geq 30$.

†Married or unmarried.

†Healthcare coverage: have health insurance, prepaid plans such as health maintenance organizations (HMOs), or government plans such as Medicare, or Indian Health Service.

§Current insulin user: 'Yes' refers to individuals using insulin at the time of the survey, 'No' refers to individuals who never used insulin or used it in the past only.

\section{DISCUSSION}

Among US adult diabetic participants, utilization of all four diabetic care practices was low (30\%), although a higher percentage (more than 60\%) of participants followed individual practices. Compared with BRFSS 2010 results, eye examinations were more common $(69 \%$ vs $62 \%$ ), daily foot checks were less common (60\% vs $71 \%$ ), whereas the frequency of blood glucose checks was similar $(61 \%$ vs $63 \%){ }^{4}$

The variability in diabetic care practices among different participants may be related to factors such as patients' knowledge gap regarding certain practices, differential access to diabetic care, personal preferences, or disease severity. For example, participants with retinopathy or on insulin treatment had higher crude and adjusted odds of performing daily blood glucose checks. These results are consistent with Harris' finding that selfmonitoring of blood glucose is rare among patients who are not treated with insulin. ${ }^{20}$

Prior studies reported mixed findings on the association between race and individual care practices. For example, Chandler and Monnat showed that, among patients aged 65 years and older with diabetes, Blacks and
Hispanics had more blood glucose checks than Whites, and Blacks and American Indians had more foot checks than Whites. ${ }^{21}$ However, Wang and Javitt reported that Black patients with diabetes had lower odds of having at least one eye care visit within a 1-year period compared with Whites. $^{22}$ In our study, a higher proportion of non-Hispanic Blacks followed diabetic care practices, compared with White participants. These findings may be partly related to Blacks having potentially greater disease severity and complications, ${ }^{23}$ which would require closer follow-up. Prior investigators had noted lower adherence to retinal screening among diabetic participants with less comorbidity. ${ }^{19}$ Greater disease severity among diabetic Blacks would also explain the previously reported higher diabetes-related mortality compared with Whites. ${ }^{24} \mathrm{~A}$ similar reason, that is, greater severity, may explain why, overall, a higher percentage of obese participants and a lower percentage of employed participants followed diabetic care practices.

After adjusting for education level and other factors, a lower proportion of participants with unhealthier behaviors (ie, lack of exercise, drinking) followed diabetes care practices compared with those without. These findings 
Table 2 Overall adherence to all four diabetes care practices by selected variables ${ }^{\star}$

\begin{tabular}{|c|c|c|c|}
\hline & Univariate & Full model & Final model \\
\hline Variables & $\begin{array}{l}\text { Crude OR } \\
(95 \% \mathrm{Cl})\end{array}$ & $\begin{array}{l}\text { Adjusted OR† } \\
(95 \% \mathrm{Cl})\end{array}$ & $\begin{array}{l}\text { Adjusted OR† } \\
(95 \% \mathrm{Cl})\end{array}$ \\
\hline \multicolumn{4}{|l|}{ Sex } \\
\hline Female versus male & $1.12(1.00$ to 1.25$)$ & 1.10 (0.98 to 1.25$)$ & - \\
\hline \multicolumn{4}{|l|}{ Age } \\
\hline $18-44$ vs $65+$ & 0.70 (0.54 to 0.89$)$ & $0.82(0.62$ to 1.08$)$ & - \\
\hline $45-64$ vs $65+$ & 0.93 (0.83 to 1.05$)$ & $1.02(0.88$ to 1.17$)$ & \\
\hline \multicolumn{4}{|l|}{ Body mass index (BMI)‡ } \\
\hline Underweight/normal weight versus obese & $0.80(0.69$ to 0.93$)$ & 0.80 (0.68 to 0.93$)$ & $0.78(0.67$ to 0.91$)$ \\
\hline Overweight versus obese & 0.91 (0.80 to 1.04$)$ & $0.93(0.82$ to 1.07$)$ & $0.92(0.81$ to 1.05$)$ \\
\hline \multicolumn{4}{|l|}{ Race/ethnicity } \\
\hline Non-Hispanic (NH) Black versus NH White & 1.66 (1.42 to 1.95$)$ & 1.77 (1.49 to 2.12$)$ & $1.77(1.48$ to 2.10$)$ \\
\hline Hispanic versus NH White & 0.84 (0.66 to 1.08$)$ & 1.01 (0.76 to 1.34$)$ & $1.01(0.76$ to 1.34$)$ \\
\hline $\mathrm{NH}$ other versus $\mathrm{NH}$ White & $0.80(0.64$ to 1.00$)$ & $0.83(0.67$ to 1.04$)$ & $0.83(0.66$ to 1.03$)$ \\
\hline \multicolumn{4}{|l|}{ Marital status } \\
\hline Widowed versus couple & $1.08(0.94$ to 1.24$)$ & 0.94 (0.80 to 1.10$)$ & 0.97 (0.83 to 1.12$)$ \\
\hline Divorced/separated/never married versus couple§ & $0.92(0.80$ to 1.05$)$ & 0.84 (0.72 to 0.98$)$ & $0.82(0.71$ to 0.95$)$ \\
\hline \multicolumn{4}{|l|}{ Education } \\
\hline High school (HS) versus $<$ HS & $1.37(1.15$ to 1.64$)$ & $1.40(1.15$ to 1.71$)$ & $1.41(1.16$ to 1.71$)$ \\
\hline Some college/technical versus $<\mathrm{HS}$ & $1.32(1.10$ to 1.59$)$ & 1.34 (1.10 to 1.64$)$ & $1.35(1.10$ to 1.64$)$ \\
\hline College versus $<\mathrm{HS}$ & $1.13(0.95$ to 1.35$)$ & 1.22 (1.00 to 1.49$)$ & $1.24(1.02$ to 1.51$)$ \\
\hline \multicolumn{4}{|l|}{ Employment } \\
\hline Home maker/student/retired versus employed & 1.46 (1.27 to 1.68$)$ & 1.30 (1.10 to 1.53$)$ & 1.36 (1.18 to 1.57$)$ \\
\hline Unemployed/unable to work versus employed & $1.60(1.35$ to 1.90$)$ & 1.43 (1.18 to 1.72$)$ & $1.44(1.20$ to 1.74$)$ \\
\hline \multicolumn{4}{|l|}{ Smoking status } \\
\hline Current versus never & 0.79 (0.65 to 0.95$)$ & $0.88(0.72$ to 1.08$)$ & - \\
\hline Former versus never & $0.98(0.87$ to 1.11$)$ & 1.04 (0.92 to 1.19$)$ & \\
\hline \multicolumn{4}{|l|}{ Alcohol intake in the past 30 days } \\
\hline Yes versus no & 0.69 (0.62 to 0.78$)$ & 0.75 (0.66 to 0.85$)$ & 0.74 (0.65 to 0.83$)$ \\
\hline \multicolumn{4}{|l|}{ Self-reported general health } \\
\hline Good/better versus fair/poor & 0.93 (0.83 to 1.04$)$ & $1.14(1.00$ to 1.30$)$ & $1.15(1.01$ to 1.31$)$ \\
\hline \multicolumn{4}{|l|}{ Healthcare coverage $\mathbb{I}$} \\
\hline Yes versus no & 2.10 (1.51 to 2.92$)$ & 1.77 (1.27 to 2.47$)$ & 1.85 (1.33 to 2.56$)$ \\
\hline \multicolumn{4}{|l|}{ Personal doctor/healthcare provider } \\
\hline Yes versus no & 1.88 (1.33 to 2.66$)$ & 1.37 (0.96 to 1.96$)$ & 1.42 (0.99 to 2.03$)$ \\
\hline \multicolumn{4}{|l|}{ Exercise in the past 30 days } \\
\hline Yes versus no & 1.13 (1.01 to 1.27$)$ & 1.27 (1.13 to 1.43$)$ & 1.26 (1.12 to 1.42$)$ \\
\hline \multicolumn{4}{|l|}{ Current insulin user ${ }^{\star *}$} \\
\hline Yes versus no & 3.00 (2.67 to 3.39$)$ & 2.97 (2.64 to 3.34$)$ & 2.95 (2.62 to 3.31$)$ \\
\hline \multicolumn{4}{|l|}{ Could not see a doctor due to cost } \\
\hline Yes versus no & $0.82(0.67$ to 1.01$)$ & $0.92(0.74$ to 1.16$)$ & - \\
\hline \multicolumn{4}{|l|}{ History of retinopathy } \\
\hline Yes versus no & 1.53 (1.33 to 1.75$)$ & 1.17 (1.01 to 1.35$)$ & 1.17 (1.01 to 1.34$)$ \\
\hline
\end{tabular}

*Sample size for univariate, full and final models: $n=30780 ; \mathrm{N}=13113662$.

†Adjusted for all other covariates in the column.

‡BMI: underweight/normal weight: $\mathrm{BMI}<25$, overweight: $25 \leq \mathrm{BMI}<30$, obese: $\mathrm{BMI} \geq 30$.

$\S$ Married or unmarried.

ףHealthcare coverage: have health insurance, prepaid plans such as health maintenance organizations (HMOs), or government plans such as Medicare, or Indian Health Service.

${ }^{* *}$ Current insulin user: 'Yes' refers to individuals using insulin at the time of the survey, 'No' refers to individuals who never used insulin or used it in the past only. 


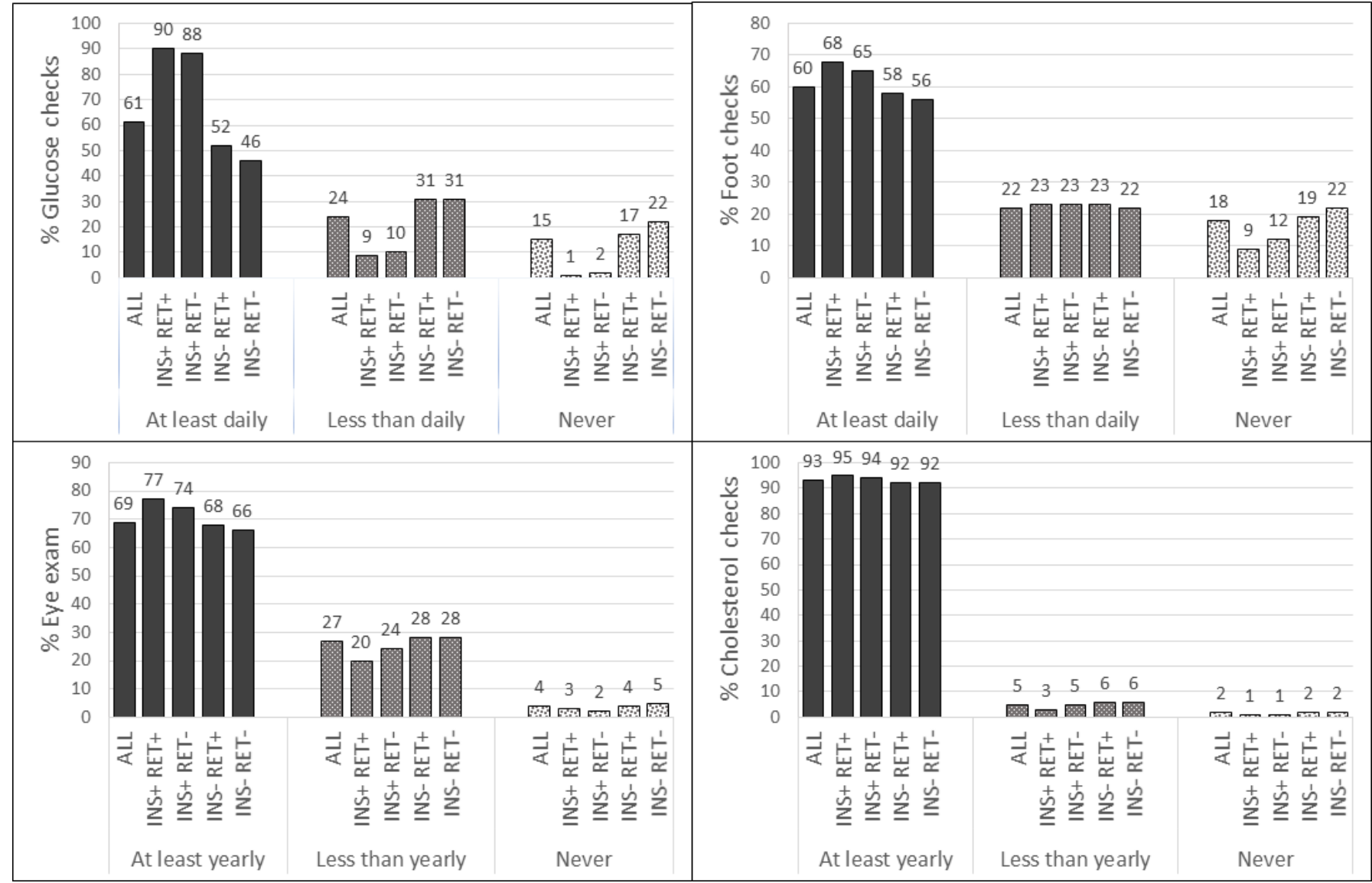

Figure 2 Diabetic care practice utilization overall and by insulin (INS) use and history of retinopathy (RET).

suggest that adherence may be linked to personal behavioral choices, independent of an individual's level of general education.

A higher proportion of participants with a personal doctor or insurance followed diabetic care practices compared with those without. These findings are consistent with previous studies of both the general and diabetic population, and suggest that factors linked to reduced access to care and financial barriers may be important determinants of low overall adherence among patients with diabetes. ${ }^{25-27}$ Additionally, our subanalysis of individual diabetic care practices showed that having a personal doctor or being insured was more strongly associated with having an annual eye examination or cholesterol check than performing daily glucose or foot checks. This finding may be explained by easier access to care and/or lower financial requirements of homebased glucose or foot checks compared with clinic-based annual eye examinations or cholesterol checks.

Limitations of this study included the use of self-reports collected at one time point, unavailability of detailed clinical profiles or prognostic outcomes, and some missing data, which might have introduced misclassification, selection or confounding bias. Additionally, since diabetes is a heterogeneous condition, our universal definition of adherence should not be interpreted as being synonymous with ADA guidelines compliance, which depends on disease severity. Strengths of this study were the use of standardized data collection procedures and the large, nationally representative sample of US adults, although certain subgroups were not represented (eg, institutionalized individuals, military and pregnant women).

\section{CONCLUSION}

In this nationally representative sample of diabetic US adults, overall implementation of diabetic care practices was low and differed across population subgroups and by type of practice. Utilization was lower among individuals with no health coverage or personal doctor, and for diabetes care practices more strongly linked to access to care.

Studies have shown that diabetic individuals do not adhere to recommended care guidelines until complications develop. ${ }^{28}$ In our study, diabetic care practices were more common among non-Hispanic Blacks, insulin users and individuals with obesity or retinopathy, which might have been related to greater disease severity in these subgroups.

These findings suggest that stronger adherence may require diabetes care practice-specific strategies, such as improved accessibility or more comprehensive insurance coverage for clinic-based practices, and targeted early education for home-based practices. Encouraging early 
Table 3 Final models for adherence to individual diabetic care practices by selected variables

\begin{tabular}{|c|c|c|c|c|}
\hline \multirow[b]{2}{*}{ Variables } & $\begin{array}{l}\text { Daily blood glucose } \\
\text { check ( } n=30516 ; \\
N=12991686)\end{array}$ & $\begin{array}{l}\text { Daily foot check } \\
(n=30244 ; N=12861 \\
213)\end{array}$ & $\begin{array}{l}\text { Annual eye } \\
\text { examination }(n=30 \\
529 ; N=13018532)\end{array}$ & $\begin{array}{l}\text { Annual cholestero } \\
\text { check }(n=30371 ; \\
N=12884320)\end{array}$ \\
\hline & $\begin{array}{l}\text { Adjusted OR* } \\
(95 \% \mathrm{Cl})\end{array}$ & $\begin{array}{l}\text { Adjusted OR* } \\
(95 \% \mathrm{Cl})\end{array}$ & $\begin{array}{l}\text { Adjusted OR* } \\
(95 \% \mathrm{Cl})\end{array}$ & $\begin{array}{l}\text { Adjusted OR* } \\
(95 \% \mathrm{Cl})\end{array}$ \\
\hline \multicolumn{5}{|l|}{ Body mass index (BMI)† } \\
\hline $\begin{array}{l}\text { Underweight/normal weight } \\
\text { versus obese }\end{array}$ & 0.91 (0.78 to 1.06$)$ & 0.80 (0.69 to 0.93$)$ & 0.92 (0.78 to 1.08$)$ & 0.61 (0.47 to 0.78$)$ \\
\hline Overweight versus obese & 0.92 (0.81 to 1.06$)$ & 0.89 (0.80 to 1.00$)$ & $1.01(0.88$ to 1.15$)$ & 0.95 (0.77 to 1.17$)$ \\
\hline \multicolumn{5}{|l|}{ Race/ethnicity } \\
\hline $\begin{array}{l}\text { Non-Hispanic (NH) Black } \\
\text { versus NH White }\end{array}$ & 1.47 (1.25 to 1.73$)$ & 1.52 (1.32 to 1.75$)$ & 1.35 (1.15 to 1.57$)$ & $1.03(0.79$ to 1.34$)$ \\
\hline Hispanic versus $\mathrm{NH}$ White & 1.27 (0.99 to 1.63$)$ & 0.87 (0.69 to 1.09$)$ & 1.00 (0.79 to 1.26$)$ & 1.07 (0.76 to 1.51$)$ \\
\hline $\mathrm{NH}$ other versus $\mathrm{NH}$ White & 0.84 (0.67 to 1.05$)$ & 0.81 (0.66 to 0.99$)$ & $1.16(0.93$ to 1.45$)$ & 0.73 (0.51 to 1.05$)$ \\
\hline \multicolumn{5}{|l|}{ Marital status } \\
\hline Widowed versus couple & $1.10(0.95$ to 1.28$)$ & 0.88 (0.76 to 1.02$)$ & 0.99 (0.84 to 1.16$)$ & 1.31 (1.01 to 1.69$)$ \\
\hline $\begin{array}{l}\text { Divorced/separated/never } \\
\text { married versus coupleł }\end{array}$ & 0.89 (0.78 to 1.02$)$ & 0.95 (0.84 to 1.07$)$ & 0.84 (0.74 to 0.95$)$ & 0.88 (0.71 to 1.08$)$ \\
\hline \multicolumn{5}{|l|}{ Education } \\
\hline High school (HS) versus $<$ HS & 0.97 (0.80 to 1.18$)$ & $1.22(1.03$ to 1.44$)$ & 1.29 (1.08 to 1.54$)$ & 0.95 (0.67 to 1.34$)$ \\
\hline $\begin{array}{l}\text { Some college/technical versus } \\
<\text { HS }\end{array}$ & $0.86(0.71$ to 1.05$)$ & 1.26 (1.06 to 1.51$)$ & 1.26 (1.05 to 1.52$)$ & $0.88(0.61$ to 1.27$)$ \\
\hline College versus $<\mathrm{HS}$ & 0.78 (0.64 to 0.95$)$ & 1.07 (0.89 to 1.29$)$ & 1.56 (1.29 to 1.89$)$ & $1.10(0.73$ to 1.64$)$ \\
\hline \multicolumn{5}{|l|}{ Employment } \\
\hline $\begin{array}{l}\text { Home maker/student/retired } \\
\text { versus employed }\end{array}$ & 1.16 (1.02 to 1.33$)$ & 1.07 (0.94 to 1.21$)$ & 1.84 (1.61 to 2.10$)$ & 2.07 (1.69 to 2.54$)$ \\
\hline $\begin{array}{l}\text { Unemployed/unable to work } \\
\text { versus employed }\end{array}$ & 1.46 (1.22 to 1.74$)$ & 1.36 (1.15 to 1.59$)$ & $1.22(1.04$ to 1.45$)$ & 1.25 (0.96 to 1.63$)$ \\
\hline \multicolumn{5}{|l|}{ Alcohol intake in the past 30 days } \\
\hline Yes versus no & 0.69 (0.62 to 0.78$)$ & 0.83 (0.75 to 0.93$)$ & $1.02(0.91$ to 1.15$)$ & 0.90 (0.74 to 1.09$)$ \\
\hline \multicolumn{5}{|l|}{ Self-reported general health } \\
\hline Good/better versus fair/poor & $0.98(0.87$ to 1.11$)$ & 0.96 (0.86 to 1.07$)$ & 1.33 (1.18 to 1.50$)$ & 0.89 (0.73 to 1.09$)$ \\
\hline \multicolumn{5}{|l|}{ Healthcare coverage§ } \\
\hline Yes versus no & 1.74 (1.36 to 2.22$)$ & $1.06(0.84$ to 1.34$)$ & 2.32 (1.86 to 2.90$)$ & 3.05 (2.30 to 4.06$)$ \\
\hline \multicolumn{5}{|l|}{ Personal doctor/healthcare provider } \\
\hline Yes versus no & 1.44 (1.09 to 1.90$)$ & 1.28 (1.01 to 1.62$)$ & 1.54 (1.23 to 1.94$)$ & 3.56 (2.73 to 4.66$)$ \\
\hline \multicolumn{5}{|l|}{ Exercise in the past 30 days } \\
\hline Yes versus no & 1.37 (1.23 to 1.54$)$ & 1.14 (1.03 to 1.26$)$ & 1.19 (1.06 to 1.33$)$ & 1.13 (0.93 to 1.38$)$ \\
\hline \multicolumn{5}{|l|}{ Current insulin userף } \\
\hline Yes versus no & 8.57 (7.35 to 9.98$)$ & 1.41 (1.26 to 1.57$)$ & 1.53 (1.36 to 1.73$)$ & 1.25 (1.01 to 1.55$)$ \\
\hline \multicolumn{5}{|l|}{ History of retinopathy } \\
\hline Yes versus no & 1.18 (1.01 to 1.38$)$ & 1.05 (0.92 to 1.21$)$ & 1.19 (1.02 to 1.38$)$ & 1.13 (0.88 to 1.46$)$ \\
\hline
\end{tabular}

${ }^{*}$ Adjusted for all other covariates in the table.

†BMI: underweight/normal weight: $\mathrm{BMl}<25$, overweight: $25 \leq \mathrm{BMI}<30$, obese: $\mathrm{BMI} \geq 30$.

†Married or unmarried.

$\S$ Healthcare coverage: have health insurance, prepaid plans such as health maintenance organizations (HMOs), or government plans such as Medicare, or Indian Health Service.

ๆCurrent insulin user: 'Yes' refers to individuals using insulin at the time of the survey, 'No' refers to individuals who never used insulin or only used it in the past. 
adherence may reduce complications and unnecessary future costs, particularly in high-risk subgroups. Given that the highest adherence was observed for annual cholesterol checks, adherence to the remaining diabetes care practices could be reinforced at the same time that a healthcare provider orders a cholesterol test.

Contributors All authors contributed to the study design and data analyses, and drafted, read and approved the manuscript.

Funding This work was partially supported by the National Institutes of Health, National Institute of General Medical Sciences (5U54GM115458).

Competing interests None declared.

Patient consent for publication Not required.

Ethics approval The Institutional Review Board (IRB) at the researchers' institution acknowledged that the analysis of deidentified and publicly available data does not constitute human subjects research as defined in US federal regulations, and does not require IRB approval.

Provenance and peer review Not commissioned; externally peer reviewed.

Data availability statement Data are available in public, open access repository.

Open access This is an open access article distributed in accordance with the Creative Commons Attribution Non Commercial (CC BY-NC 4.0) license, which permits others to distribute, remix, adapt, build upon this work non-commercially, and license their derivative works on different terms, provided the original work is properly cited, appropriate credit is given, any changes made indicated, and the use is non-commercial. See: http://creativecommons.org/licenses/by-nc/4.0/.

ORCID iD

Fang Yu http://orcid.org/0000-0003-2243-5788

\section{REFERENCES}

1 World Health Organization Geneva. Global report on diabetes, 2016. Available: https://www.who.int/diabetes/global-report/en/ [Accessed Aug 2020].

2 Centers for Disease Control and Prevention (CDC) Atlanta GA. Your diabetes care schedule, 2019. Available: https://www.cdc.gov/ diabetes/managing/care-schedule.html [Accessed Aug 2020].

3 American Diabetes Association. Introduction: Standards of Medical Care in Diabetes-2020. Diabetes Care 2020;43:S1-2.

4 Chen R, Cheadle A, Johnson D, et al. Us trends in receipt of appropriate diabetes clinical and self-care from 2001 to 2010 and racial/ethnic disparities in care. Diabetes Educ 2014;40:756-66.

5 Carroll MD, Kit BK, Lacher DA. Total and high-density lipoprotein cholesterol in adults, 2009-2010. NCHS data brief no 92. Hyattsville, MD: National Center for Health Statistics, 2012.

6 Fowler MJ. Microvascular and macrovascular complications of diabetes. Clinical Diabetes 2008;26:77-82.

7 Benjamin EM. Self-Monitoring of blood glucose: the basics. Clinical Diabetes 2002;20:45-7.

8 Singh N, Armstrong DG, Lipsky BA. Preventing foot ulcers in patients with diabetes. JAMA 2005;293:217-28.

9 Krishnan S, Nash F, Baker N, et al. Reduction in diabetic amputations over 11 years in a defined U.K. population: benefits of multidisciplinary team work and continuous prospective audit. Diabetes Care 2008;31:99-101.

10 Yazdanpanah L, Nasiri M, Adarvishi S. Literature review on the management of diabetic foot ulcer. World J Diabetes 2015;6:37-53

11 Zhao Y-X, Chen X-W. Diabetes and risk of glaucoma: systematic review and a meta-analysis of prospective cohort studies. Int $J$ Ophthalmol 2017;10:1430-5.

12 Kiziltoprak H, Tekin K, Inanc M, et al. Cataract in diabetes mellitus. World J Diabetes 2019;10:140-53.

13 Cheung N, Mitchell P, Wong TY. Diabetic retinopathy. Lancet 2010;376:124-36.

14 Willis JR, Doan QV, Gleeson M, et al. Self-Reported healthcare utilization by adults with diabetic retinopathy in the United States. Ophthalmic Epidemiol 2018;25:365-72.

15 Muñoz B, O'Leary M, Fonseca-Becker F, et al. Knowledge of diabetic eye disease and vision care guidelines among Hispanic individuals in Baltimore with and without diabetes. Arch Ophthalmol 2008;126:968-74.

16 Zhang X, Cotch MF, Ryskulova A, et al. Vision health disparities in the United States by race/ethnicity, education, and economic status: findings from two nationally representative surveys. $A m \mathrm{~J}$ Ophthalmol 2012;154:S53-62.

17 Centers for Disease Control Prevention (CDC). Behavioral Risk Factor Surveillance System user's guide. Atlanta GA: US Department of Health and Human Services, Centers for Disease Control and Prevention, 2017.

18 Karter AJ, Ferrara A, Darbinian JA, et al. Self-Monitoring of blood glucose: language and financial barriers in a managed care population with diabetes. Diabetes Care 2000;23:477-83.

19 Brown DW, Balluz LS, Giles WH, et al. Diabetes mellitus and health-related quality of life among older adults. findings from the behavioral risk factor surveillance system (BRFSS). Diabetes Res Clin Pract 2004;65:105-15.

20 Harris MI. Racial and ethnic differences in health care access and health outcomes for adults with type 2 diabetes. Diabetes Care 2001;24:454-9.

21 Chandler RF, Monnat SM. Racial/Ethnic differences in use of health care services for diabetes management. Health Educ Behav 2015;42:783-92.

22 Wang F, Javitt JC. Eye care for elderly Americans with diabetes mellitus. failure to meet current guidelines. Ophthalmology 1996;103:1744-50

23 Hazel-Fernandez L, Li Y, Nero D, et al. Racial/Ethnic and gender differences in severity of diabetes-related complications, health care resource use, and costs in a Medicare population. Popul Health Manag 2015;18:115-22.

24 Spanakis EK, Golden SH. Race/ethnic difference in diabetes and diabetic complications. Curr Diab Rep 2013;13:814-23.

25 Zhang X, Saaddine JB, Lee PP, et al. Eye care in the United States: do we deliver to high-risk people who can benefit most from it? Arch Ophthalmol 2007;125:411-8.

26 Nelson KM, Chapko MK, Reiber G, et al. The association between health insurance coverage and diabetes care; data from the 2000 behavioral risk factor surveillance system. Health Serv Res 2005;40:361-72.

27 Li Y-J, Xirasagar S, Pumkam C, et al. Vision insurance, eye care visits, and vision impairment among working-age adults in the United States. JAMA Ophthalmol 2013;131:499-506.

28 Suzuki S. Association between diabetic complications and frequency of $\mathrm{HbA1c}$ checks in the United States-Analysis of the 2015 behavioral risk factors surveillance system (BRFSS) data, 2018. Available: https://unthsc-ir.tdl.org/handle/20.500.12503/27996 [Accessed Aug 2020]. 